\title{
Temporal changes in the distinct scattered wave packets associated with earthquake swarm activity beneath the Moriyoshi-zan volcano, northeastern Japan
}

\author{
Yuta Amezawa* (iD, Masahiro Kosuga and Takuto Maeda
}

\begin{abstract}
We investigated temporal changes in the waveforms of S-coda from triggered earthquakes around the Moriyoshizan volcano in northeastern Japan. Seismicity in the area has drastically increased after the 2011 off the Pacific coast of Tohoku earthquake, forming the largest cluster to the north of the volcano. We analyzed distinct scattered wave packets (DSW) that are S-to-S scattered waves from the mid-crust and appeared predominantly at the high frequency range. We first investigated the variation of DSW for event groups with short inter-event distances and high crosscorrelation coefficients (CC) in the time window of direct waves. Despite the above restriction, DSW showed temporal changes in their amplitudes and shapes. The change occurred gradually in some cases, but temporal trends were much more complicated in many cases. We also found that the shape of DSW changed in a very short period of time, for example, within $\sim 12 \mathrm{~h}$. Next, we estimated the location of the origin of the DSW (DSW origin) by applying the semblance analysis to the data of the temporary small-aperture array deployed to the north of the largest cluster of triggered events. The DSW origin is located between the largest cluster within which hypocentral migration had occurred and the low-velocity zone depicted by a tomographic study. This spatial distribution implies that the DSW origin was composed of geofluid-accumulated midway in the upward fluid movement from the low-velocity zone to the earthquake cluster. Though we could not entirely exclude the possibility of the effect of the event location and focal mechanisms, the temporal changes in DSW waveforms possibly reflect the temporal changes in scattering properties in and/or near the origin. The quick change in DSW waveforms implies that fast movement of geofluid can occur at the depth of the mid-crust.
\end{abstract}

Keywords: Coda waves, Scattering, Triggered earthquakes, Seismic swarm, Geofluid, The 2011 off the Pacific coast of Tohoku earthquake

\footnotetext{
*Correspondence: h19ds201@hirosaki-u.ac.jp

Graduate School of Science and Technology, Hirosaki University, 3

Bunkyo-cho, Hirosaki, Aomori 036-8561, Japan
}

\section{Introduction}

Seismic swarms consist of small earthquakes that cause no damage, but they attract much attention from seismologists who are keen to study the contributions of geofluid to the generation of earthquakes. Swarm activity occurs in areas near volcanoes, around injection wells, and sometimes in locations apart from big earthquakes. Among these types of activity, the induced earthquakes
\end{abstract}

caused by artificial fluid injections for wastewater disposal or enhancement of geothermal systems have received not only scientific interest, but social concern as well because often these occur in places where no notable seismicity has occurred prior to the injection (e.g., Deichmann and Giardini 2009; Ellsworth 2013; Rubinstein and Mahani 2015). The earlier analyses of injection-induced earthquakes have enabled us to infer the behavior of fluid in the crust (e.g., Shapiro et al. 2002; Terakawa 2014; Mukuhira et al. 2017).

A recent example of triggered seismicity after big earthquakes is the seismic swarms in many areas in 
Japan after the 2011 off the Pacific coast of Tohoku earthquake ( $M w 9.0$; hereafter referred to as the Tohoku earthquake) (e.g., Okada et al. 2011, 2015; Kosuga et al. 2012; Terakawa et al. 2013; Yoshida et al. 2019). Hypocenter migration is a common feature of triggered swarms (e.g., Okada et al. 2015). Since the migration is often observed during fluid injection experiments (e.g., Shapiro et al. 1997), and with seismic swarms at volcanoes (e.g., Battaglia et al. 2005; Yukutake et al. 2011, Shelly et al. 2015, 2016) as well, many researchers have suggested the evolution of pore fluid pressure as the cause of the triggered seismicity (Kosuga 2014; Okada et al. 2015; Yoshida and Hasegawa 2018a, b).

One of the most active swarms triggered by the Tohoku earthquake occurred in the area around the Quaternary Moriyoshi-zan volcano in northern Tohoku (Fig. 1). The seismic activity started about 2 months after the Tohoku earthquake and has continued for more than 8 years. Hypocenter migration was observed in the most massive cluster located at approximately $5 \mathrm{~km}$ to the north of the volcano (Fig. 1b). The migration started from the bottom of the southeastern part of the cluster (red dots in Fig. 1c) to the northeastern part and changed direction to the west. The activity was illuminated by several bursts of small clusters and showed upward migration. Detailed features of the spatiotemporal migration were described by Kosuga (2014).

A notable feature of seismograms from the triggered earthquakes around the Moriyoshi-zan volcano is the appearance of distinct wave packets after the arrival of $\mathrm{S}$-waves (Fig. 2). The waveform of the packets is considerably different from that of direct waves: they do not have clear onset, and they always appear almost same timing after the direct $\mathrm{S}$-wave onset. In addition, the packets have much longer duration than that of the direct S-waves. All of these characteristics suggest that the packets are scattered waves originated from medium inhomogeneities rather than independent microearthquakes or reflected waves. Hereafter, we refer these packets as distinct scattered wave packets (DSW). By using the time difference between S-waves and DSW among several clusters, Kosuga (2014) estimated the scatterer locations assuming S-to-S scattering. We can see the inter-event variation of DSW in Figure 10 of Kosuga (2014), but the factor of this variation has not been well studied.

In this study, we report on the features of DSW, in particular, temporal changes in waveforms observed around the Moriyoshi-zan volcano. We first collect seismograms from nearly the same source location and analyze the spatial and temporal variations. Then, we estimate the locations of the origin of DSW (hereafter referred to as DSW origin) by using the semblance analysis technique applied to data from a temporary small-aperture array. Finally, considering the behavior of temporal changes in DSW and the estimated DSW origin, we discuss the convincing factors for the temporal changes in DSW.

\section{DSW and temporal changes \\ Waveform types of DSW}

Figure 2 shows examples of DSW observed at a Hi-net (National Research Institute for Earth Science and Disaster Resilience 2019) station N.ANIH and two temporary stations HR.MAS1 (one of the component stations of the array) and HR.MRY. The scattered phase had an approximately $1 \mathrm{~s}$ duration and S-wave like behavior (Kosuga 2014). Though the time difference between $S$-waves and DSW was almost constant among the events in each cluster, waveforms of DSW varied considerably (Figure 10 of Kosuga 2014).

The waveforms of DSW were roughly classified into the following three types: (A) single peak, (B) double peaks, and $(C)$ unclear. We performed this classification by visual inspection of the seismograms observed at N.ANIH during the period from May 2011 to November 2016. The resultant proportion of each type was (A) $33.8 \%$, (B) $63.0 \%$, and $(C) 3.2 \%$.

To investigate if the earthquakes of the three types were separated in space, we relocated the hypocenters by the HypoDD method (Waldhauser and Ellsworth 2000). We followed the procedures in Kosuga (2014) but for the events with the extended period from March 2011 to November 2016. We used catalog data only. Travel-time data were mostly taken from the unified catalog of the Japan Meteorological Agency (JMA), but we added manually picked data from one of the authors for temporary stations. In total, we used 115,212 picks from the JMA catalog and 13,813 manual picks. The relocated hypocenters (e.g., Fig. 3) showed a strongly clustered distribution dipping eastward, as previously reported by Kosuga (2014).

Hypocenter distributions of events classified into the three types showed that there were no clear separations among the types of DSW (Fig. 3). The earthquakes almost overlapped between types A and B, though earthquakes of type B formed some concentrated clusters. The hypocenters of type $\mathrm{C}$ were localized on the northeastern side of the whole events space, but they were less than the numbers of other types. These facts indicate that the waveform type is insensitive to the hypocentral location. This may be partly related to the insufficient accuracy of the event location.

\section{Temporal changes in DSW}

To further examine the waveforms of DSW for collocated events, we used the following two thresholds: 

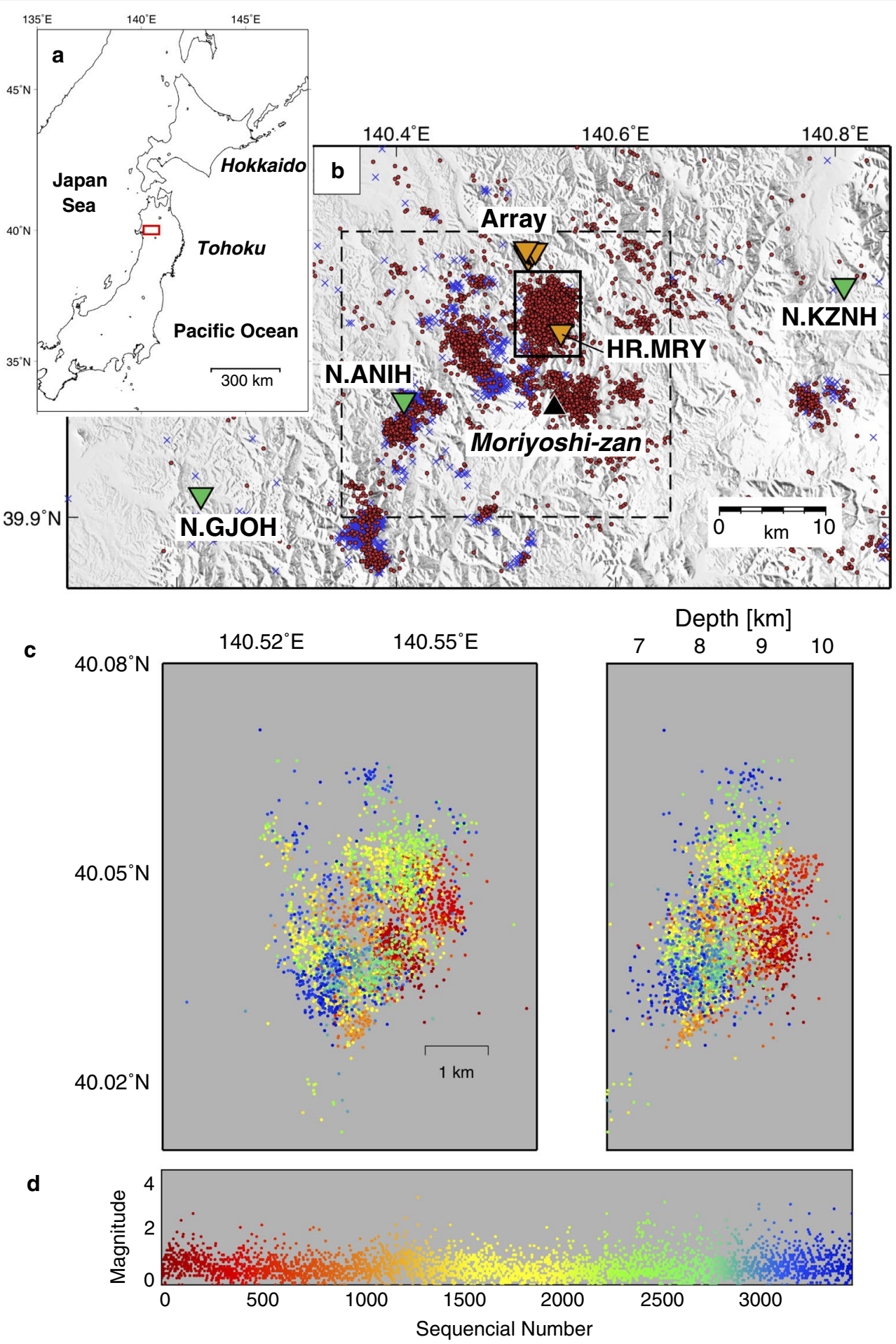

Fig. 1 Hypocenter distribution around the Moriyoshi-zan volcano. a Index map. b Areal map of the study area showing shallow seismicity ( $\leq 15 \mathrm{~km}$ ) before and after the Tohoku earthquake (blue crosses: January 2006-March 2011; red circles: March 2011-November 2016) from the unified catalog of the Japan Meteorological Agency (JMA). The solid rectangle represents the largest cluster in which hypocenter migration was observed. The broken rectangle represents the area shown in Figs. 2, 8, and 9. Green and orange inverted triangles denote Hi-net and temporary seismic stations, respectively. c Relocated hypocenter distribution in the largest cluster in $\mathbf{b}$. Color of the circles shows the chronological sequential number of earthquakes in the period from March 2011 to November 2016. d Magnitude versus sequential number plot 


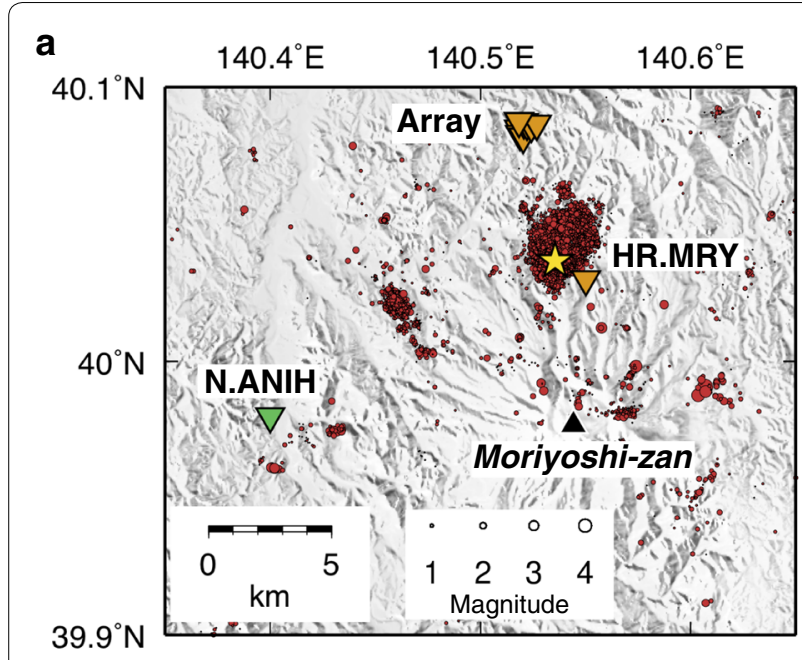

C
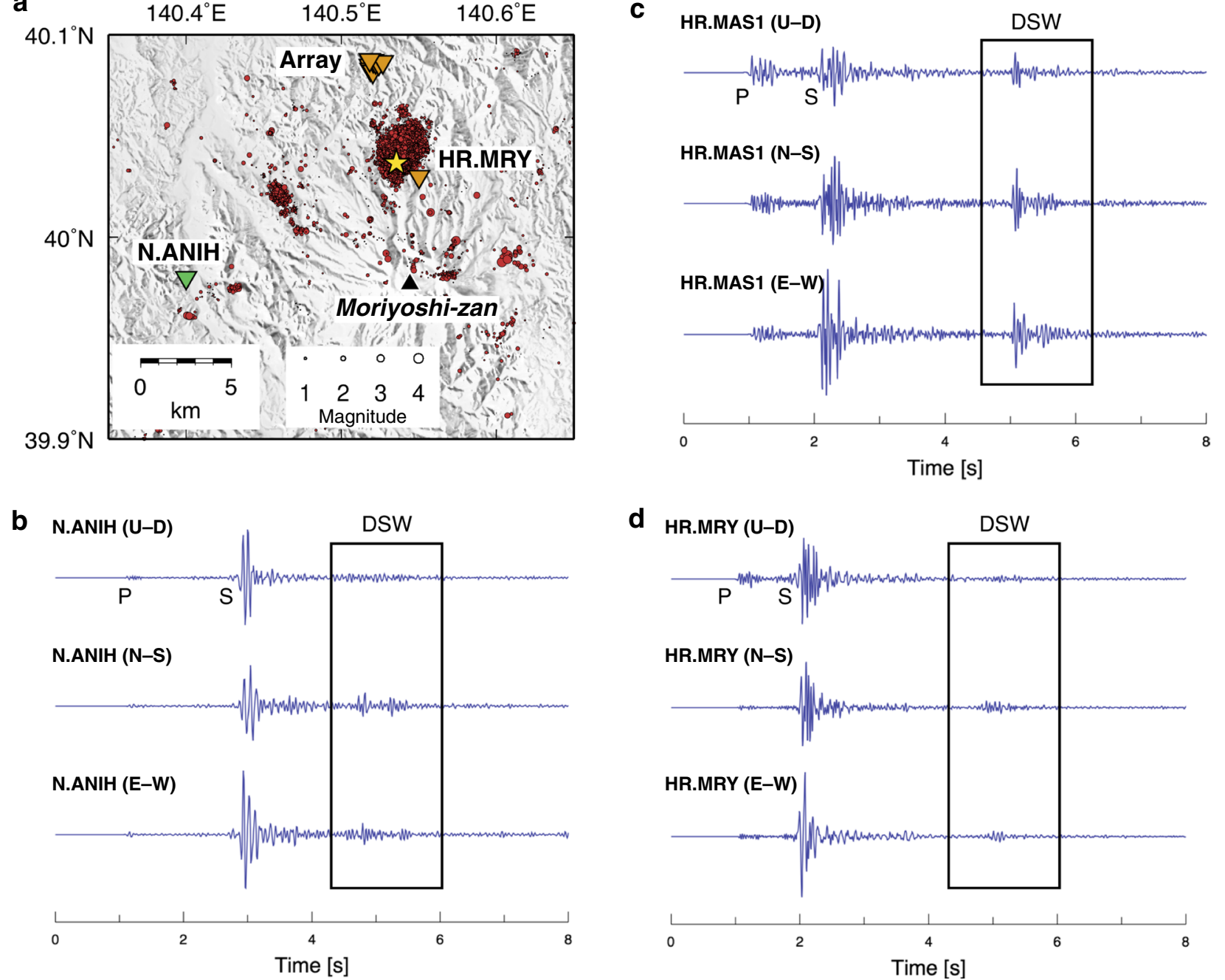

Fig. 2 An example of DSW (distinct scattered wave packets). a Location of the epicenter (yellow star) and stations (inverted triangles). Red circles and black triangle denote the epicenter of earthquakes and the location of the Moriyoshi-zan volcano, respectively. b-d Three-component band-pass filtered (8-32 Hz) seismograms from the earthquake (November 9, 2012, 03:46:37 JST (UT+9), M2.7) observed at the stations shown in $\mathbf{a}$. HR.MAS1 is one of the component stations of the array. The amplitude is normalized to the maximum among the three components. DSW appears in the black rectangles

inter-event distance and cross-correlation coefficient of the direct waves. We collected events in a grid with a size of $1 \mathrm{~km}$ for the $\mathrm{N}-\mathrm{S}, \mathrm{E}-\mathrm{W}$, and depth directions. Then, after applying a band-pass filter of $2-16 \mathrm{~Hz}$, we calculated the cross-correlation coefficient (CC) of both the direct $\mathrm{P}$ - and $\mathrm{S}$-waves for all event pairs in the grid. We calculated the CC from the vertical component for P-waves and from the two horizontal components for $\mathrm{S}$-waves, at three Hi-net stations surrounding the grid (N.ANIH, N.KZNH, N.GJOH; Fig. 1b). The length of the time window was $1 \mathrm{~s}$. We adopted event pairs having an average $C C \geq 0.85$ as members of a group with similar waveforms. We repeated this procedure by moving the grid with an overlap of $0.5 \mathrm{~km}$ to the neighboring grid.

Figure 4 shows examples of the envelopes belonging to some groups. To improve visibility of the DSW, we applied an auto gain control technique to the seismogram envelope. In this technique, the envelope amplitude is modified by multiplying coefficient reciprocal to the RMS amplitude of the envelope within a moving time window of $0.1 \mathrm{~s}$, resulting in the enhancement of DSW that have much smaller amplitude than the direct $\mathrm{S}$-waves.

Since DSW are dominant in a higher frequency range than that of the CC calculations $(2-16 \mathrm{~Hz})$, we show band-pass filtered envelopes with the passband 

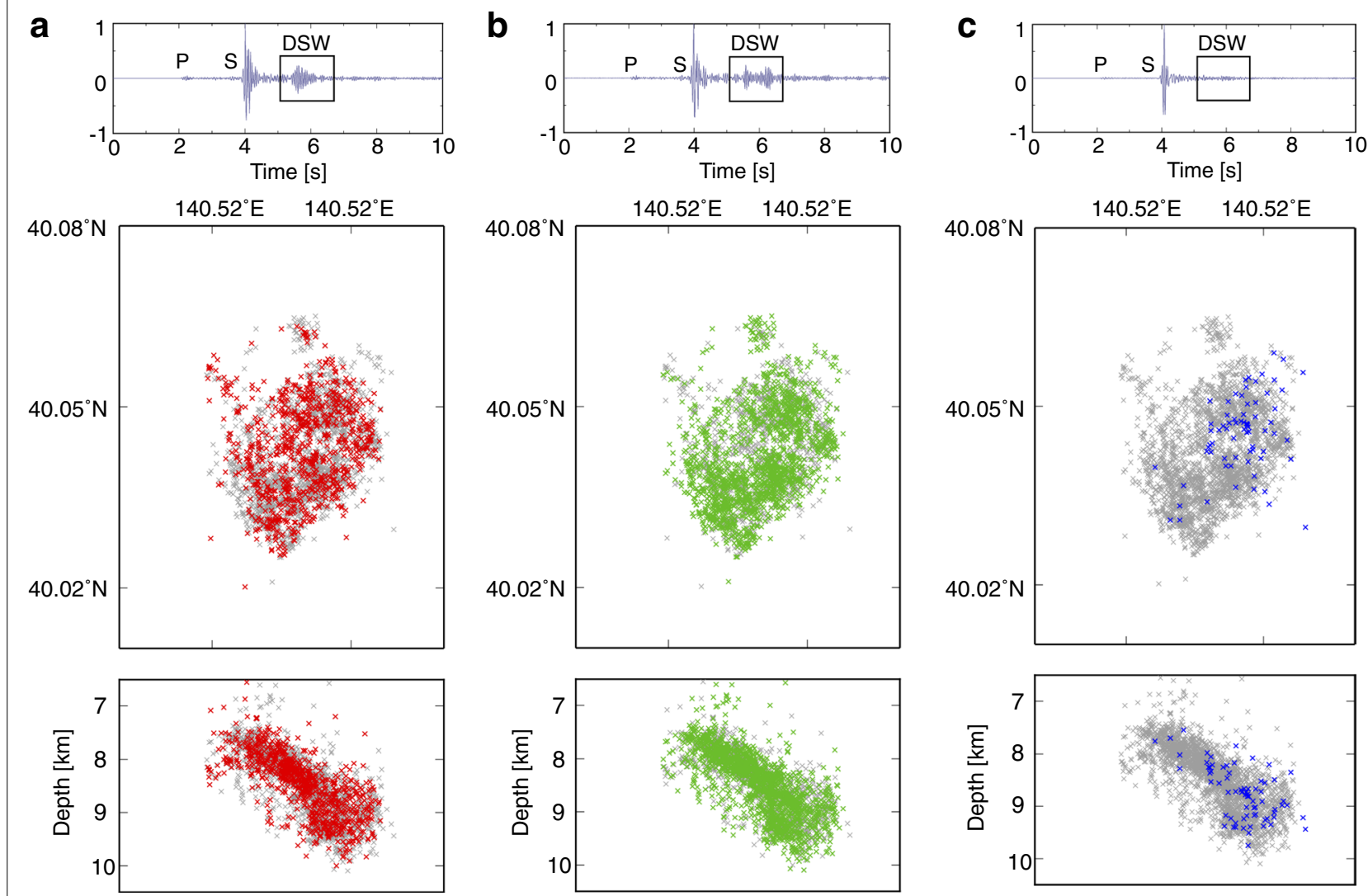

Fig. 3 Three types of DSW and the corresponding hypocenter distribution. Top figures represent seismograms with DSW classified as a single peak (a), double peaks (b), and unclear (c), respectively. Middle and bottom figures show epicenter and depth distribution of earthquakes. Colored and gray crosses denote the hypocenters of each type of DSW and whole earthquakes, respectively

of 8-24 Hz. The hypocenter distributions of the events displayed in Fig. 4 are shown in Fig. 5.

In general, the waveforms of $\mathrm{P}$ - and S-waves were very similar as we applied two thresholds to ensure the event collocation. Some peaks in P-coda (Fig. 4b, d) were found to have been due to successive earthquakes. Despite the similarity of direct waves, many DSW showed temporal changes in their amplitudes and shapes. For example, in Fig. 4a, the amplitudes of DSW increased with time, and the shapes of DSW changed from a type of unclear peak to another type of clear double peaks. This was a case of systematic change. However, most changes in DSW were much more complicated (e.g., Fig. 4d, e). We also found that DSW shapes changed significantly in a very short time interval, for example, within $\sim 12 \mathrm{~h}$ (Fig. 6).

Observed significant changes in DSW can be attributed to either the source effect or the scatterer effect. We will discuss this again after estimating the DSW origin.

\section{The origin of DSW Array data}

We estimated the DSW origin by using data from a small seismometer array operated during the period from November 2012 to May 2014. Kosuga (2014) used a portion of this dataset for hypocenter location and envelope analyses. The L-shaped array located at approximately $10 \mathrm{~km}$ north of the Moriyoshi-zan volcano had nine stations with an average spacing of about $150 \mathrm{~m}$ and an arm length of about $700 \mathrm{~m}$ (Fig. 7). The maximum height difference among the stations was $49 \mathrm{~m}$. Each station was equipped with $1-\mathrm{Hz}$ threecomponent seismometers. The recording was continuous with a sampling frequency of $100 \mathrm{~Hz}$ and a 24-bit resolution. 
a Grid: 122

Envelope

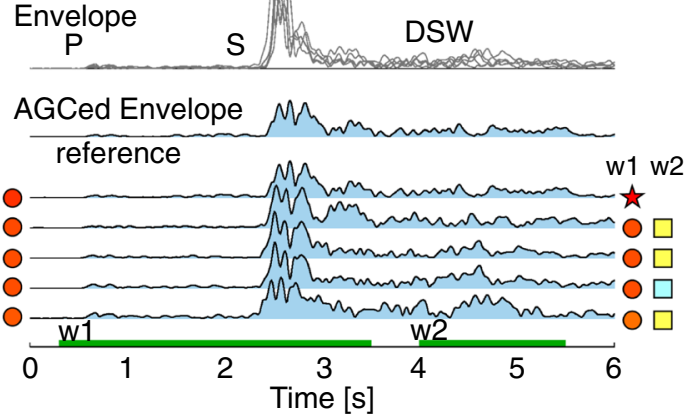

b Grid: 125

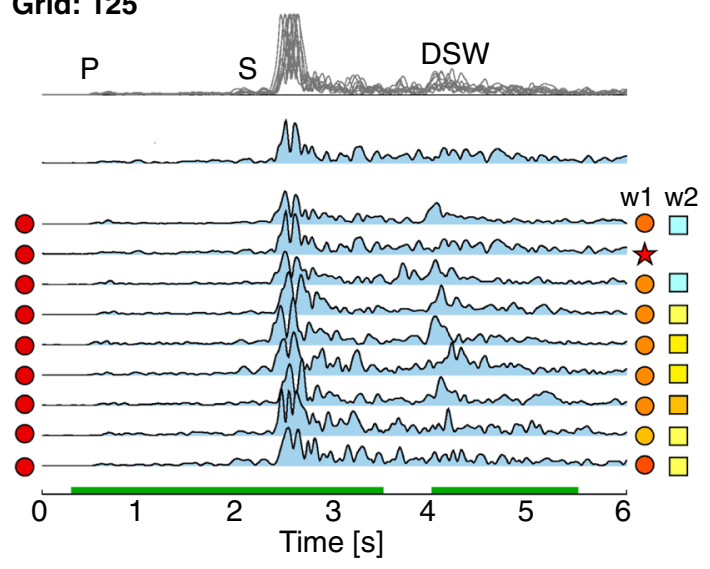

C Grid: 132

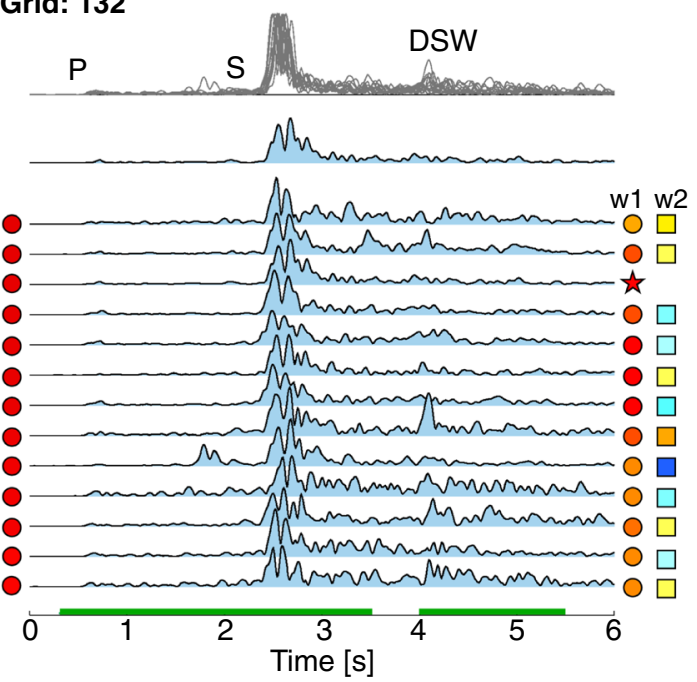

d Grid: 159

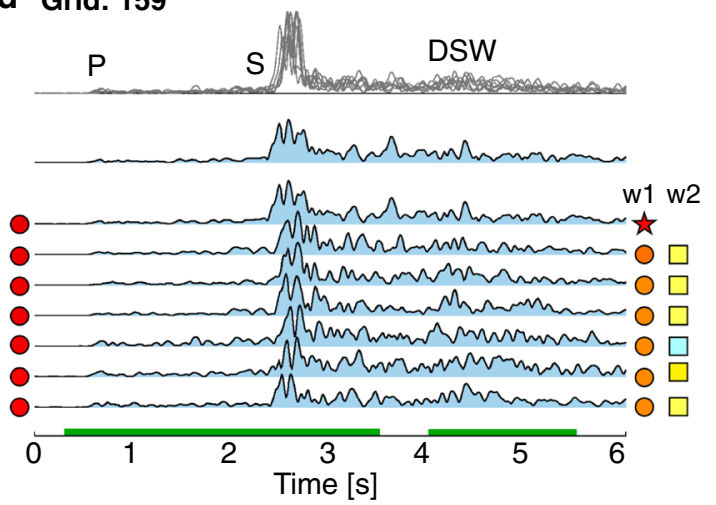

e Grid: 164

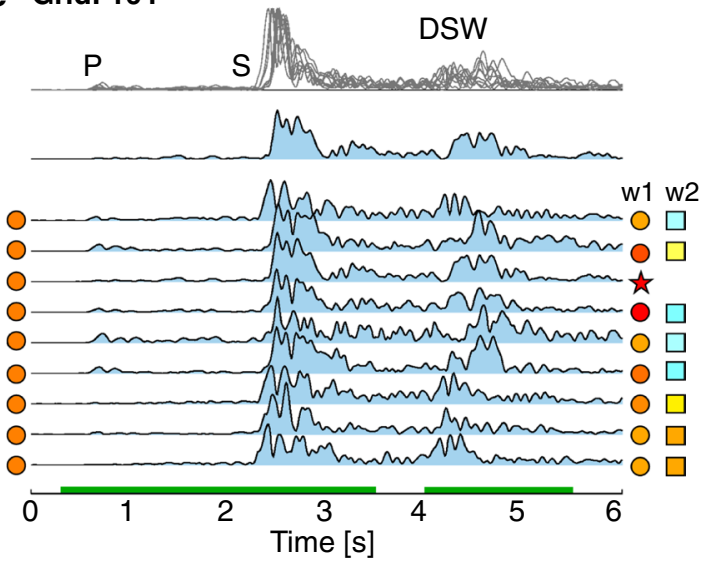

f Grid: 167
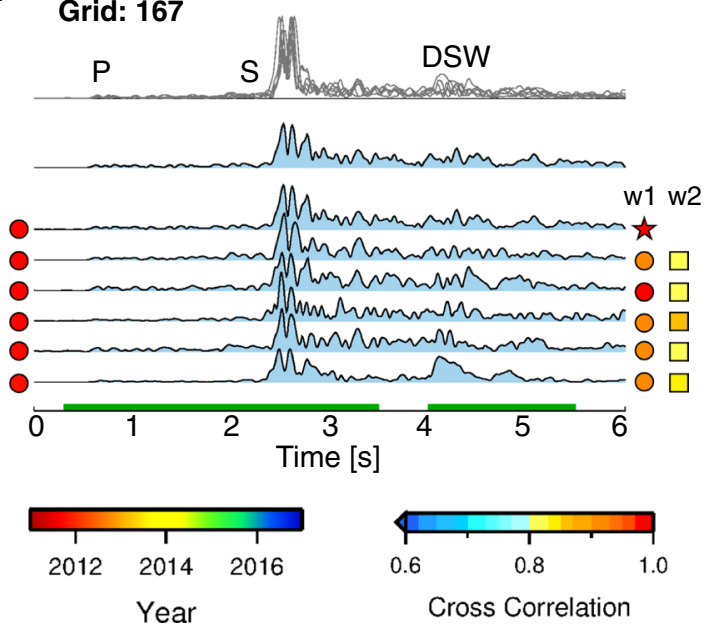

Fig. $4 \mathrm{~N}$-S component band-pass filtered $(8-24 \mathrm{~Hz})$ envelopes for events with similar waveform of direct waves at hypocenter grid numbers of a 122, b 125, c 132, d 159, e 164, and f 167. Gray lines on the top in each panel show the overwriting of envelopes. Colored envelopes were modified by applying auto gain control to improve the visibility of the DSW. Color of circles on the left-hand side of envelopes shows the year of event occurrence. Color of circles and squares on the right-hand side of envelopes represents the cross-correlation for direct wave and DSW to the reference event marked by a star. Green lines on the time axis indicate the time window of CC calculations. All traces are aligned with P-wave onset 

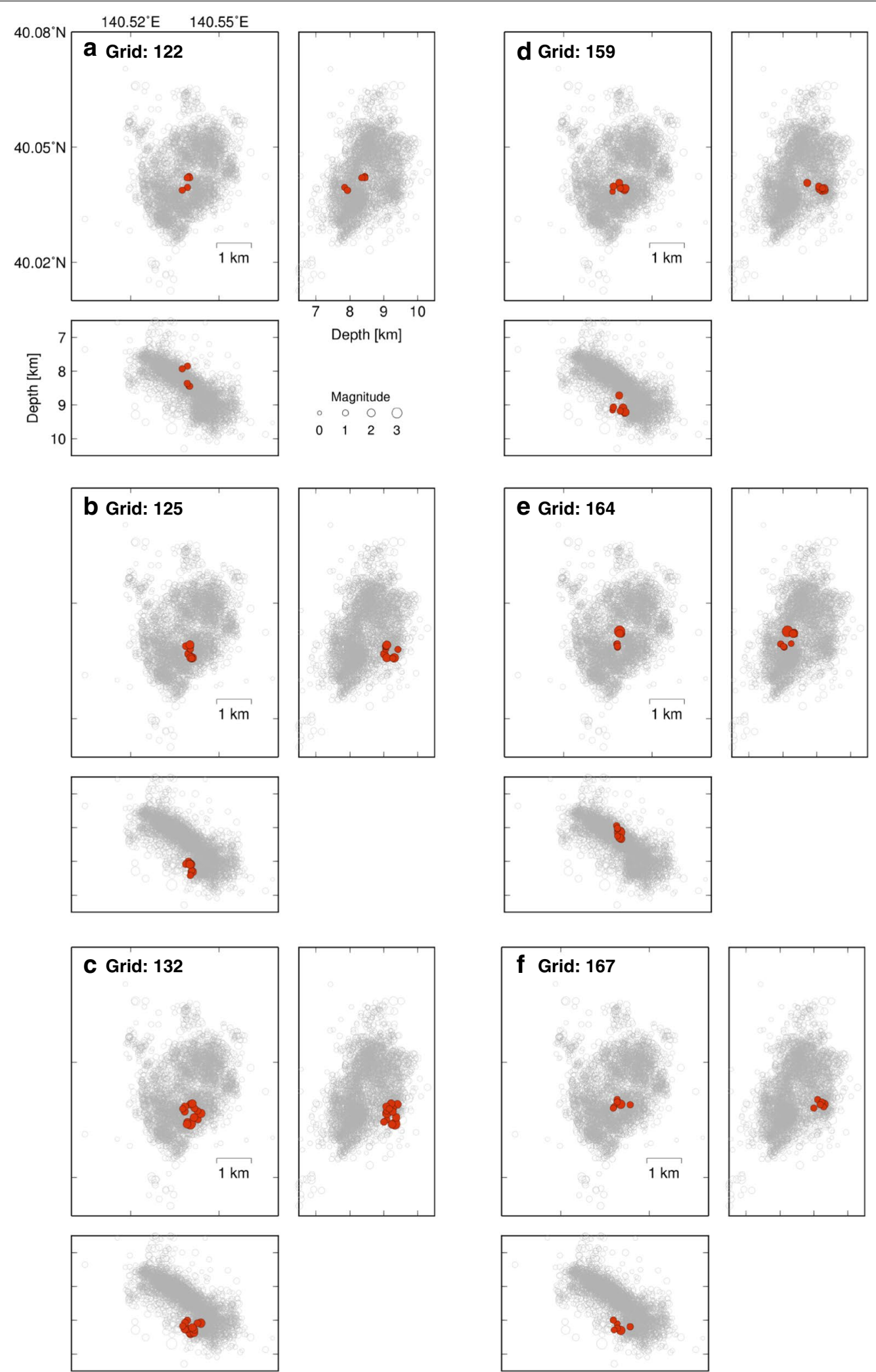

Fig. 5 Relocated hypocenter distribution of the events in groups a-f with similar waveform shown in Fig. 4 (solid red circles). Gray circles denote the hypocenter distribution of whole earthquakes 

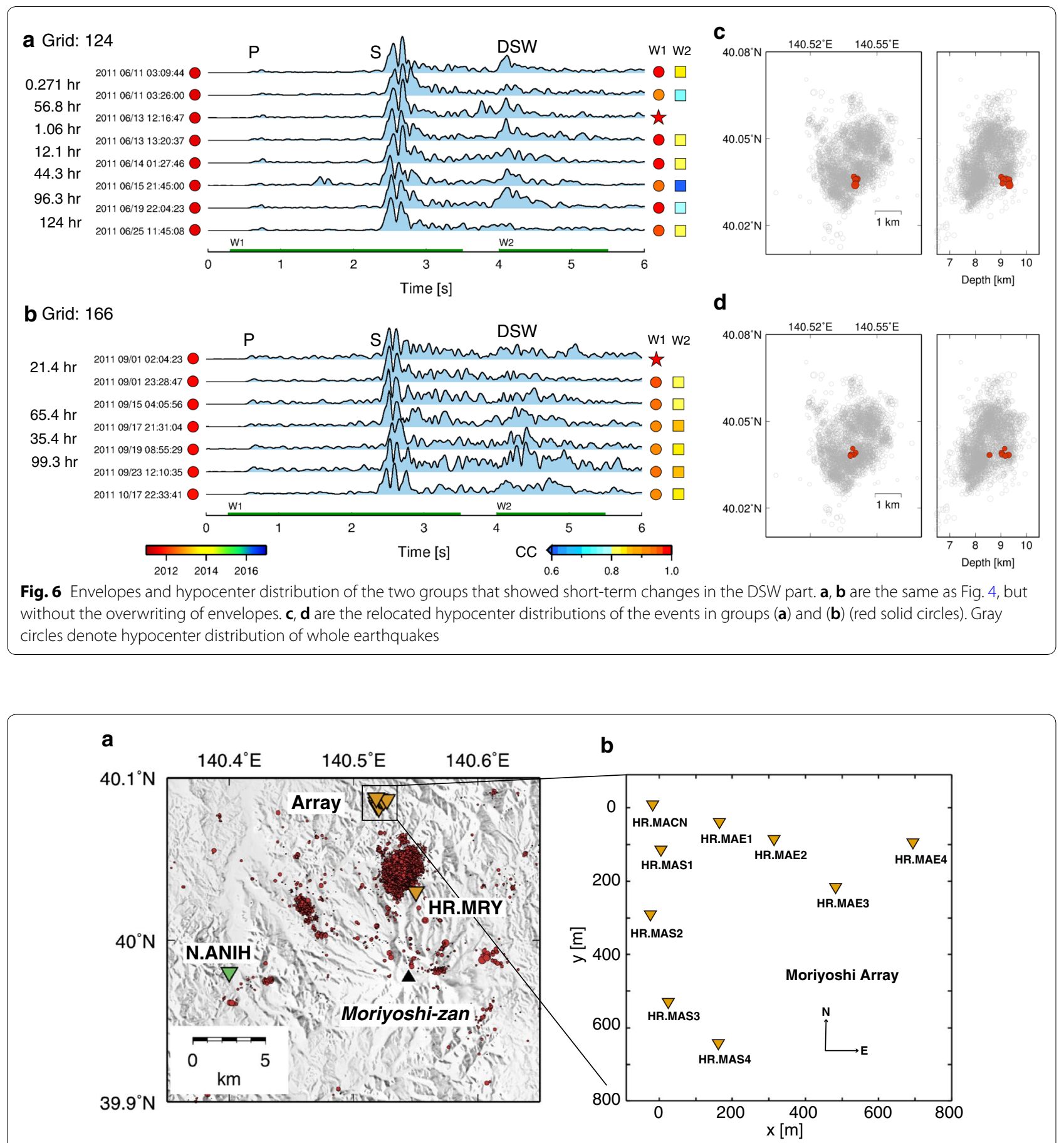

Fig. 7 a Location of the array. Green and orange inverted triangles represent Hi-net and temporary seismic stations, respectively. Red circles denote epicenters of earthquakes occurred during the period from March 2011 to November 2016. b Station distribution of the array. Orange inverted triangles represent the component stations of the array

\section{Semblance analysis}

To estimate the apparent slowness and the incident azimuth of DSW, we applied the semblance analysis technique (Neidell and Taner 1971) to DSW observed by the array. We estimated these values by calculating the semblance value given by 


$$
S\left(t, s_{x}, s_{y}\right)=\frac{\sum_{j=1}^{M}\left[\sum_{i=1}^{N} u_{i}\left(t_{j}-\tau_{i}+T_{0 i}\right)\right]^{2}}{N \sum_{j=1}^{M} \sum_{i=1}^{N} u_{i}\left(t_{j}-\tau_{i}+T_{0 i}\right)^{2}},
$$

where $s_{x}$ and $s_{y}$ are the $x$ - and $y$-component of the apparent slowness, respectively, $N$ is the number of stations, $u_{i}\left(t_{j}\right)$ is the amplitude of the waveform observed at discretized time $t_{j}$ at the $i$ th station, $M$ is the number of samples in the time window, and $\tau_{i}$ is the travel time difference between the $i$ th and reference stations. Time $T_{0 i}$ denotes a travel-time correction to compensate for the differences in the altitudes of array stations. The length of the time window was set to $0.33 \mathrm{~s}$. The semblance values were calculated for band-pass filtered seismograms with a passband of $3-12 \mathrm{~Hz}$ and by shifting time windows with an interval of $0.067 \mathrm{~s}$. In each time window, semblance values were calculated for a range of slowness, $-0.5 \mathrm{~s} / \mathrm{km} \leq s_{x}, \quad s_{y} \leq 0.5 \mathrm{~s} / \mathrm{km}$, and with a step of $0.025 \mathrm{~s} / \mathrm{km}$.

Figure 8 shows an example of the semblance analysis. The semblance values for $\mathrm{P}$ - and $\mathrm{S}$-waves have sharp peaks both in the incident azimuth and apparent slowness. The incident azimuth agrees well with the back azimuth of the epicenter (Fig. 8c, pink line). About $3 \mathrm{~s}$ after the S-wave arrival, DSW appeared with lower apparent slowness than that of the S-wave, especially in the horizontal components. The incident azimuth and apparent slowness of DSW were estimated to be $\sim 180^{\circ} \mathrm{N}$ and $\sim 0.15 \mathrm{~s} / \mathrm{km}$, respectively. The average of maximum semblance values for DSW from the E-W component was higher than that from the $\mathrm{N}-\mathrm{S}$ component. Thus, we used the results from the E-W component for the following analysis.

\section{Estimation of the DSW origin}

Next, we located the DSW origin under the assumption of S-to-S single scattering. The data were the estimated values of incident azimuth and incident angle for DSW with semblance values larger than or equal to $90 \%$ of the maximum value $(0.90)$. The time differences between the arrival time of P-wave and DSW were set as 3.8-4.5 s taking into account the range of the arrival times of DSW. We divided up the area around the array $\left(39.9^{\circ} \mathrm{N}-40.2^{\circ} \mathrm{N}, 140.35^{\circ} \mathrm{E}-140.70^{\circ} \mathrm{E}\right.$, depth $\left.0-15 \mathrm{~km}\right)$ into grids of $0.005^{\circ} \times 0.005^{\circ} \times 2 \mathrm{~km}$. We then calculated the incident azimuth, incident angle, and travel time difference between P-waves and DSW for a hypothetical scatterer location at a particular grid point. We added a score for grid points which satisfy the criteria of (1) slowness of DSW estimated by semblance analysis, (2) back-azimuth of DSW estimated by semblance analysis, and (3) arrival time difference between P-wave and DSW. We performed this procedure for each event we analyzed and obtained the map of scores. For the calculation of travel time, we assumed a homogeneous medium with $\mathrm{Vp}=5.8 \mathrm{~km} / \mathrm{s}$ and $\mathrm{Vs}=3.5 \mathrm{~km} / \mathrm{s}$. By repeating this
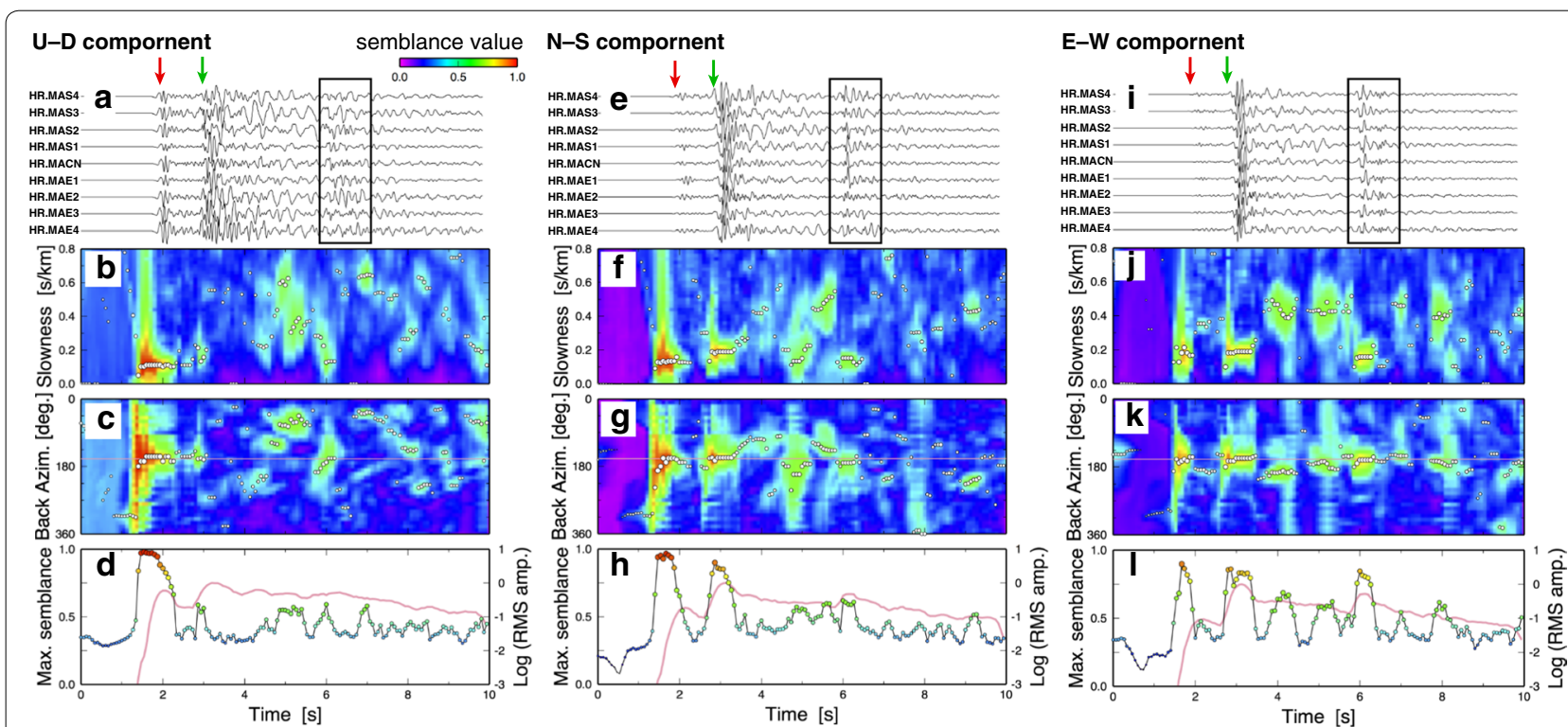

Fig. 8 An example of semblance analysis for three-component seismograms from the earthquake (November 25, 2012, 07:55:17 JST (UT + 9), M2.8). Four panels in each component are, from top to bottom, seismograms $(\mathbf{a}, \mathbf{e}$, and $\mathbf{i})$, slowness $(\mathbf{b}, \mathbf{f}$, and $\mathbf{j})$, back-azimuth $(\mathbf{c}, \mathbf{g}$, and $\mathbf{k})$, and maximum semblance value together with the RMS envelope $(\mathbf{d}, \mathbf{h}$, and $\mathbf{I})$, respectively. The background color in slowness and back-azimuth plots represents semblance values. Circles in the same panels denote the slowness and back-azimuth with the maximum semblance value in every time step. The red and green arrows indicate the arrival times of P-and S-waves, respectively. Pink lines in $\mathbf{c}, \mathbf{g}$, and $\mathbf{k}$ indicate the back-azimuth to the event epicenter 


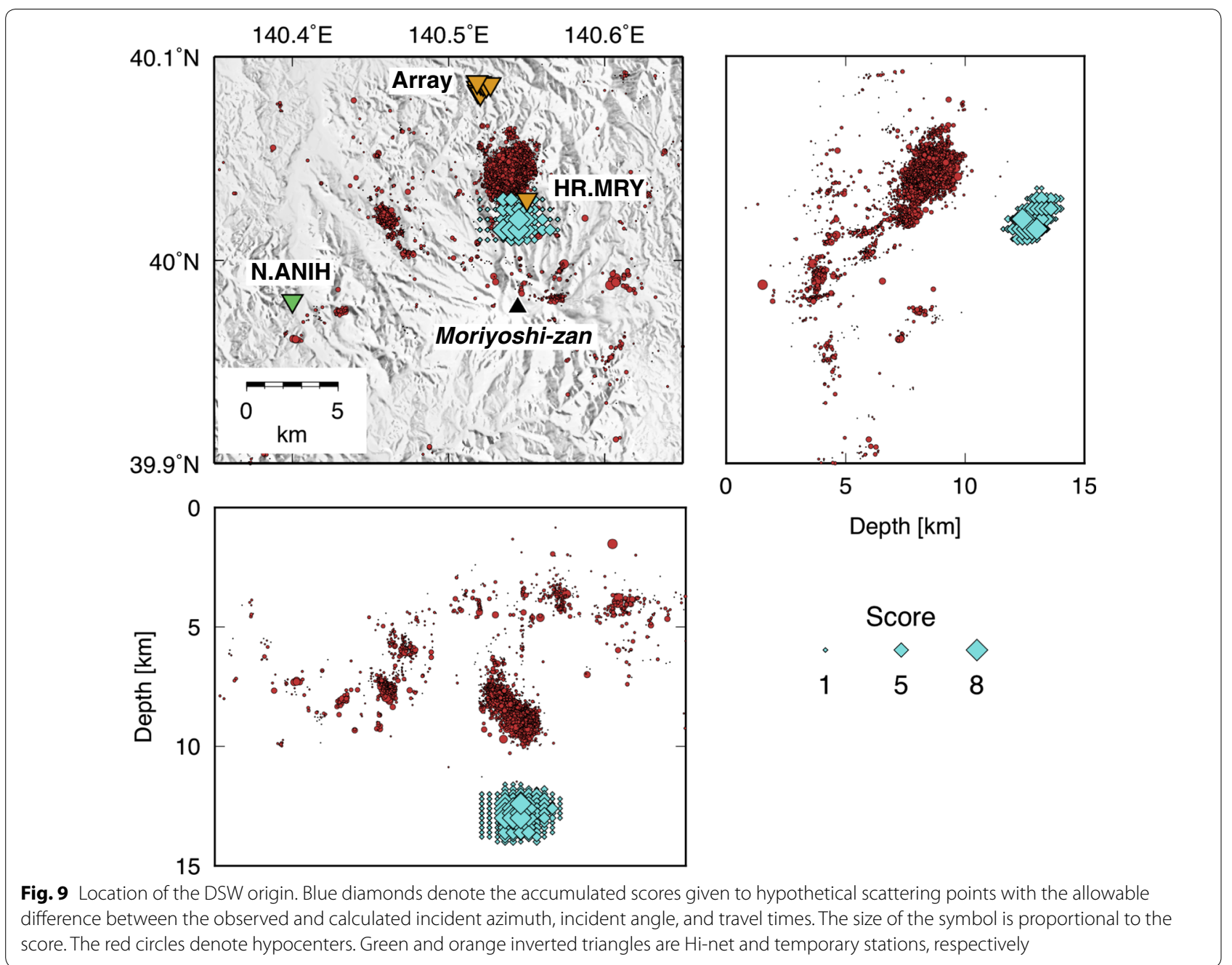

procedure for all combinations of grid points and swarm events, we obtained a spatial distribution of scores, from which we estimated the DSW origin as grid points with high scores.

Figure 9 shows the spatial distribution of scores. An area of high scores, i.e., the DSW origin was located about $5 \mathrm{~km}$ north of the Moriyoshi-zan volcano and an approximate depth of $13 \mathrm{~km}$. The DSW origin estimated in this study had shifted about $5 \mathrm{~km}$ northeast from the best-estimated location proposed by Kosuga (2014), who used a method analogous to the source-scanning algorithm (Kao and Shan 2004). Though the difference between the two locations was in a range of high brightness obtained by the source scanning, we think that the azimuthal restriction from the array analysis was better.

\section{Discussion}

\section{Interpretation of the estimated DSW origin}

The estimated DSW origin was beneath the northern seismic cluster in which hypocentral migration was observed (Fig. 9). According to tomographic results around the Moriyoshi-zan volcano (Okada et al. 2015), there is a low-velocity zone just below the DSW origin, which implies the existence of geofluid.

Before the Tohoku earthquake, the dominant type of focal mechanisms in the Tohoku region was E-W compressional reverse fault that reflects westward subduction of the Pacific plate. However, after the Tohoku earthquake, a significant number of strike-slip earthquakes occurred not only in the investigated area but in the other area of triggered seismicity located about $50 \mathrm{~km}$ to the south (e.g., Kosuga et al. 2012; Okada et al. 2015). This change means that the direction of $\sigma_{2}$ became vertical. According to Sibson (1996), strong directional permeability may develop in the $\sigma_{2}$ direction within the mesh structure. Yoshida et al. (2012) calculated the coseismic stress change as small as less than $1 \mathrm{MPa}$ in the northern Tohoku region. To explain the change in the focal mechanisms under such small stress fluctuation, Terakawa et al. (2013) suggested the reactivation of pre-existing faults 
due to the increase in pore fluid pressure. Thus, if the structural condition is met in the Moriyoshi-zan area, geofluid will tend to move upward from the low-velocity zone to the source area of triggered seismicity. Upward hypocenter migration of the seismic cluster just above the DSW origin (Fig. 1c) also supports the hypothesis.

\section{The plausible factors for the temporal changes in DSW}

In this study, we used waveform-correlation thresholds to group the events within a cluster. Even by choosing the events with similar waveforms for direct waves and with close distances of hypocenters, we found that the DSW waveforms were considerably different from each other (Figs. 4 and 6). These changes can be more plausibly attributed to the path effect rather than the differences in source location or focal mechanisms.

Possible path effects are the temporal change in the attenuation and/or scattering properties of the DSW origin. Temporal changes in the attenuation coefficient were reported under a fluid-rich condition. Wcisło et al. (2018) reported a statistically significant temporal decrease in the effective attenuation coefficient that is consistent with an observed increase in $\mathrm{CO}_{2}$ upwelling flow within about 1.5 months during the 2008 West Bohemia seismic swarm. Matsumoto et al. (2001) reported a quick temporal change in the location of the scattering source around the Iwate volcano, northeastern Japan. They found that the scattering source moved several kilometers in the period before and after an M6.1 earthquake, a time frame of about 3 months, and interpreted the change as possible fluid migration. These results may be attributed to temporal change in geofluid distribution, as fluid can move with time. Since the waveforms of DSW examined in this study sometimes changed over short intervals of hours or days (Fig. 6), the fluid must have moved very fast.

Kosuga (2014) estimated the hydraulic diffusivity (D) (Shapiro et al. 1997) from the hypocenter migration observed in the same cluster that we examined in this study. The diffusivity $D$ amounted to $\sim 0.01 \mathrm{~m}^{2} / \mathrm{s}$ across the entire investigation period, and the values were in the range of 0.05 to $0.1 \mathrm{~m}^{2} / \mathrm{s}$ for the initial stage of seismic activity. He noted that the diffusivity varied from 0.01 to $0.7 \mathrm{~m}^{2} / \mathrm{s}$ over shorter time intervals. These values are comparable to those in other cases, for example, a value of $0.5 \mathrm{~m}^{2} / \mathrm{s}$ derived from injectioninduced seismicity (Shapiro et al. 1997) and values of $0.5-1.0 \mathrm{~m}^{2} / \mathrm{s}$ (Yukutake et al. 2011) and $0.25-0.5 \mathrm{~m}^{2} / \mathrm{s}$ (Shelly et al. 2015) derived from swarm activity around active volcanoes. In Fig. 4, we can see that the peak of DSW fluctuates in the range of $0.1-0.3 \mathrm{~s}$. If we assume the fluctuation reflects the position of the DSW origin, the above range corresponds to a position shift of $0.35-$ $1.05 \mathrm{~km}$, assuming Vs $=3.5 \mathrm{~km} / \mathrm{s}$. By using the highest value of diffusivity around the Moriyoshi-zan volcano $\left(0.7 \mathrm{~m}^{2} / \mathrm{s}\right)$, the time for earthquake migration over the above distances was estimated to have ranged from 3.9 to $34 \mathrm{~h}$, which is consistent with the time interval for short-term shape changes of DSW. Note that the time is for the expansion of the migration front and not for fluid movement; however, rough agreement in terms of the order of the above times suggests that geofluid can move quickly and contribute to the temporal variation of DSW. One of the other plausible causes of rapid change in the DSW is the drastic spatiotemporal change in the elastic properties of the DSW origin. Migration of volatile component such as $\mathrm{CO}_{2}$ in geofluid can lead the change as suggested by Wcisło et al. (2018).

Recently, Zhu et al. (2019) reported that they could monitor a continuous velocity reduction by analyzing scattering coda waves during the dynamic injection of $\mathrm{CO}_{2}$ in Texas. Similar monitoring can be done in other areas using natural earthquakes, though the source location is not unique. This study shows that the monitoring of coda waves has the potential to reveal the spatiotemporal evolution of scatterers. Required refinement, for example, rigorous event selection and statistical grouping of DSW, is the next step of this research.

\section{Conclusions}

We investigated the temporal changes in the waveforms of DSW observed around the Moriyoshi-zan volcano in northern Tohoku by using the grouped events of similar waveforms for direct waves. Despite the similarity of direct waves, many of the DSW showed temporal changes in their amplitudes and shapes. In some cases, the change occurred gradually. However, most changes in DSW were much more complicated. We also found that the shape of DSW changed within a very short time interval of $\sim 12 \mathrm{~h}$. We then estimated the DSW origin from semblance analysis. The location was beneath the northern seismic cluster in which hypocentral migration was observed, and just above the low-velocity zone beneath the volcano. This spatial distribution suggests the existence of geofluid in the DSW origin. Though we could not entirely exclude the possibility of effects of the event location and focal mechanisms, we gave preference to the change in scattering properties in and/or near the origin because of its proximity to the low-velocity zone and earthquake cluster. The observations of rapid temporal changes in DSW waveforms are suggestive of the fast movement of geofluid in and around the DSW origin, which provides an interesting target for further studies. 


\section{Abbreviations}

DSW: distinct scattered wave packets; CC: cross-correlation coefficient; RMS: root mean square; JMA: Japan Meteorological Agency; NIED: National Research Institute for Earth Science and Disaster Resilience.

\section{Acknowledgements}

We thank Takahiro Shiina of the Earthquake Research Institute, University of Tokyo, for very valuable discussions that helped improve this study. We are grateful to two anonymous reviewers for their comments, which were very helpful for improving manuscript.

\section{Authors' contributions}

MK conceived the presented idea and performed array observations. YA and MK performed the data analyses. All authors contributed to the discussion and writing of the manuscript. All authors read and approved the final manuscript.

\section{Funding}

This study was supported by the Ministry of Education, Culture, Sports, Science and Technology (MEXT) of Japan, under its Earthquake and Volcano Hazards Observation and Research Program (HRS_01). This study was supported by JSPS KAKENHI Grant Numbers 21109002 and $15 \mathrm{H} 01135$.

\section{Availability of data and materials}

The continuous seismic waveform data of Hi-net used in this study are available via the National Research Institute for Earth Science and Disaster Resilience (https://doi.org/10.17598/nied.0003). The HypoDD (Waldhauser and Ellsworth 2000) program code was obtained from an established website (https://www.ldeo.columbia.edu/ felixw/hypoDD.html). Portions of the travel time data for relocating hypocenter locations are available via Japan Meteorological Agency (http://www.data.jma.go.jp/svd/eqev/data/bulletin/). Topography data used for constructing the figures were downloaded from the Geospatial Information Authority of Japan (http://www.gsi.go.jp/kiban/ index.html). Figures in this paper were drawn by using the Generic Mapping Tools (GMT) developed by Wessel and Smith (1998). We obtained the GISMO Toolbox-Seismic Data Analysis in MATLAB developed by Thompson and Reyes (2017) from an established website (https://github.com/geoscience-commu nity-codes/GISMO/wiki/GISMO-Analytics) (accessed June 2018), and this was used for the waveform analysis. We obtained The Seismic Analysis Code (SAC) developed by Goldstein and Snoke (2005) from an established website (http:// ds.iris.edu/ds/nodes/dmc/software/downloads/sac/), and this was used for the waveform analysis.

\section{Competing interests}

The authors declare that they have no competing interests.

Received: 1 July 2019 Accepted: 23 November 2019

Published online: 02 December 2019

\section{References}

Battaglia J, Ferrazzini V, Staudacher T, Aki K, Cheminée JL (2005) Pre-eruptive migration of earthquakes at the Piton de la Fournaise volcano (Réunion Island). Geophys J Int 161:549-558. https://doi.org/10.1111/j.1365246X.2005.02606.X

Deichmann N, Giardini D (2009) Earthquakes induced by the stimulation of an enhanced geothermal system below Basel (Switzerland). Seismol Res Lett 80:784-798. https://doi.org/10.1785/gssrl.80.5.784

Ellsworth WL (2013) Injection-induced earthquakes. Science 341(6142):1225942. https://doi.org/10.1126/science.1225942

Goldstein P, Snoke A (2005) SAC availability for the IRIS community. Incorporated Institutions for Seismology Data Management Center Electronic Newsletter

Kao H, Shan SJ (2004) The source-scanning algorithm: mapping the distribution of seismic sources in time and space. Geophys J Int 157:589-594. https://doi.org/10.1111/j.1365-246X.2004.02276.x

Kosuga M (2014) Seismic activity near the Moriyoshi-zan volcano in Akita Prefecture, northeastern Japan: implications for geofluid migration and a midcrustal geofluid reservoir. Earth Planets Space 66:77. https://doi. org/10.1186/1880-5981-66-77
Kosuga M, Watanabe K, Hashimoto K, Kasai H (2012) Seismicity in the northern part of Tohoku District induced by the 2011 off the Pacific Coast of Tohoku Earthquake. Zisin (J Seismol Soc Jpn 2nd Ser) 65:69-83. https:// doi.org/10.4294/zisin.65.69 (in Japanese with English abstract)

Matsumoto S, Obara K, Yoshimoto K, Saito T, Ito A, Hasegawa A (2001) Temporal change in P-wave scatterer distribution associated with the $M$ 6.1 earthquake near Iwate volcano, northeastern Japan. Geophys J Int 145:48-58. https://doi.org/10.1111/j.1365-246X.2001.00339.x

Mukuhira Y, Dinske C, Asanuma H, Ito T, Häring MO (2017) Pore pressure behavior at the shut-in phase and causality of large induced seismicity at Basel, Switzerland. J Geophys Res Solid Earth 122:411-435. https://doi. org/10.1002/2016JB013338

National Research Institute for Earth Science and Disaster Resilience (2019), NIED Hi-net, National Research Institute for Earth Science and Disaster Resilience, https://doi.org/10.17598/nied.0003

Neidell NS, Taner MT (1971) Semblance and other coherency measures for multichannel data. Geophysics 36:482-497. https://doi. org/10.1190/1.1440186

Okada T, Yoshida K, Ueki S, Nakajima J, Uchida N, Matsuzawa T, Umino N, Hasegawa A (2011) Shallow inland earthquakes in NE Japan possibly triggered by the 2011 off the Pacific coast of Tohoku Earthquake. Earth Planets Space 63:44. https://doi.org/10.5047/eps.2011.06.027

Okada T, Matsuzawa T, Umino N, Takahashi H, Yamada T, Kosuga M, Takeda T, Kato A, Igarashi T, Obara K, Sakai S, Saiga A, lidaka T, Iwasaki T, Hirata N, Tsumura N, Yamanaka Y, Terakawa T, Nakamichi H, Okuda T, Horikawa S, Katao H, Miura T, Kubo A, Matsushima T, Goto K, Miyamachi H (2015) Hypocenter migration and crustal seismic velocity distribution observed for the inland earthquake swarms induced by the 2011 Tohoku-Oki earthquake in NE Japan: implications for crustal fluid distribution and crustal permeability. Geofluids 15:293-309. https://doi.org/10.1111/gfl.12112

Rubinstein JL, Mahani AB (2015) Myths and facts on wastewater injection, hydraulic fracturing, enhanced oil recovery, and induced seismicity. Seismol Res Lett 86:1060-1067. https://doi.org/10.1785/0220150067

Shapiro SA, Huenges E, Borm G (1997) Estimating the crust permeability from fluid-injection-induced seismic emission at the KTB site. Geophys J Int 131:15-18. https://doi.org/10.1111/j.1365-246X.1997.tb01215.x

Shapiro SA, Rothert E, Rath V, Rindschwentner J (2002) Characterization of fluid transport properties of reservoirs using induced microseismicity. Geophysics 67:212-220. https://doi.org/10.1190/1.1451597

Shelly DR, Taira TA, Prejean SG, Hill DP, Dreger DS (2015) Fluid-faulting interactions: fracture-mesh and fault-valve behavior in the February 2014 Mammoth Mountain, California, earthquake swarm. Geophys Res Lett 42:5803-5812. https://doi.org/10.1002/2015GL064325

Shelly DR, Ellsworth WL, Hill DP (2016) Fluid-faulting evolution in high definition: connecting fault structure and frequency-magnitude variations during the 2014 Long Valley Caldera, California earthquake swarm. J Geophys Res Solid Earth 121:1776-1795. https://doi.org/10.1002/2015J B012719

Sibson RH (1996) Structural permeability of fluid-driven fault-fracture meshes. J Struct Geol 18:1031-1042. https://doi.org/10.1016/0191-8141(96)00032 $-6$

Terakawa T (2014) Evolution of pore fluid pressures in a stimulated geothermal reservoir inferred from earthquake focal mechanisms. Geophys Res Lett 41:7468-7476. https://doi.org/10.1002/2014GL061908

Terakawa T, Hashimoto C, Matsu'ura M (2013) Changes in seismic activity following the 2011 Tohoku-oki earthquake: effects of pore fluid pressure. Earth Planet Sci Lett 365:17-24. https://doi.org/10.1016/j.eosl.2013.01.017

Thompson G, Reyes C (2017) GISMO_a seismic data analysis toolbox for MATLAB [Software Package]

Waldhauser F, Ellsworth WL (2000) A double-difference earthquake location algorithm: method and application to the northern Hayward fault, California. Bull Seismol Soc Am 90:1353-1368. https://doi.org/10.1785/01200 00006

Wcisło M, Eisner L, Málek J, Fischer T, Vlček J, Kletetschka G (2018) Attenuation in West Bohemia: evidence of high attenuation in the Nový Kostel focal zone and temporal change consistent with $\mathrm{CO}_{2}$ degassing. Bull Seismol Soc Am 108:450-458. https://doi.org/10.1785/0120170168

Wessel P, Smith WHF (1998) New, improved version of the Generic Mapping Tools releases. Eos Trans AGU 79:579 
Yoshida K, Hasegawa A (2018a) Hypocenter migration and seismicity pattern change in the Yamagata-Fukushima border, NE Japan, caused by fluid movement and pore pressure variation. J Geophys Res Solid Earth 123:5000-5017. https://doi.org/10.1029/2018JB015468

Yoshida K, Hasegawa A (2018b) Sendai-Okura earthquake swarm induced by the 2011 Tohoku-Oki earthquake in the stress shadow of NE Japan: detailed fault structure and hypocenter migration. Tectonophysics 733:132-147. https://doi.org/10.1016/j.tecto.2017.12.031

Yoshida K, Hasegawa A, Okada T, linuma T, Ito Y, Asano Y (2012) Stress before and after the 2011 great Tohoku-oki earthquake and induced earthquakes in inland areas of eastern Japan. Geophys Res Lett 39:L03302. https://doi.org/10.1029/2011GL049729

Yoshida K, Hasegawa A, Yoshida T, Matsuzawa T (2019) Heterogeneities in stress and strength in tohoku and its relationship with earthquake sequences triggered by the 2011 M9 Tohoku-Oki earthquake. Pure Appl Geophys 176:1335-1355. https://doi.org/10.1007/s00024-018-2073-9
Yukutake Y, Ito H, Honda R, Harada M, Tanada T, Yoshida A (2011) Fluidinduced swarm earthquake sequence revealed by precisely determined hypocenters and focal mechanisms in the 2009 activity at Hakone volcano, Japan. J Geophys Res Solid Earth 116:B4308. https://doi. org/10.1029/2010JB008036

Zhu T, Ajo-Franklin J, Daley TM, Marone C (2019) Dynamics of geologic $\mathrm{CO}_{2}$ storage and plume motion revealed by seismic coda waves. PNAS 116:2464-2469. https://doi.org/10.1073/pnas.1810903116

\section{Publisher's Note}

Springer Nature remains neutral with regard to jurisdictional claims in published maps and institutional affiliations.

\section{Submit your manuscript to a SpringerOpen ${ }^{\circ}$ journal and benefit from:}

- Convenient online submission

- Rigorous peer review

- Open access: articles freely available online

- High visibility within the field

- Retaining the copyright to your article

Submit your next manuscript at $\boldsymbol{\nabla}$ springeropen.com 